\title{
Research on Location Choice of Vertically FDI
}

\author{
Zuo Yushan \\ Shenyang No. 1 High School \\ Shenyang, P.R.China \\ Ln_2002@126.com
}

\author{
Zhang Yanbo \\ School of Business Administration, Northeast \\ University \\ Shenyang, P.R.China \\ zyanb@163.com、
}

\begin{abstract}
By adopting the analytical frame of Dixit \& Stiglitz, this paper tries to build up a more comprehensive theoretical model of vertical FDI location. This model comprehensively generalizes factors impacting on FDI location, which investigates the location factors of host country including wage cost, transaction cost, agglomerative economy, market scale and the quality of labor force how to influence the investment location of vertical FDI. The analysis show that the location factors of the host country have dissimilar driving and affecting functions function upon vertical FDI, Therefore the government should carry on effectively choosing and matching policy tool while drawing up vertical FDI.
\end{abstract}

Keywords- investment location;monopolistic competition; vertical ly FDI; multinational enterprise

\section{INTRODUCTION}

China exceeded the United States to become the biggest FDI absorption country in 2003, and the bulk of FDI has flowed into China was vertical FDI in contrast to developed countries.

Documents on FDI are extremely abundant, but many are at the aspect of positive study. On the positive study some scholars investigate the motive, the decision process and location factors of FDI via questionnaire survey or case research; Some scholars make use of systemic data and econometrics model to reveal the relationship between foreign investment and various districts variables. Since 80 's in the 20th century, the research on FDI location mainly develops towards two aspects, one of which is to laid particular emphasis on turning the existing theory to an "clearly structural form", Namely tries to build up a general equilibrium theoretical model on FDI behaviors, A large numbers of economists including E.Helpman, J. Markusen and P.Krugman etc. concentrate on the research. Since 80s' Markusen \& Venables subdivided FDI into vertically and horizontally types, and brought them into the general equilibrium analysis frame which is held in esteem by the international trade theory circles. The work of Helpman and Markusen represented academic forward position of this aspect. The multinational company models of Markusen (1984), Brainard (1997), Markusen \& Venables (1998, 2000) emphasized the influence of transaction cost, scale economy and market scale upon the multinational company activity, but have never investigated location influence of agglomerative factors, market structure and labor force quality and so on for multinational company FDI, particularly not included the important NEG factor agglomerative economy. On the theoretical research, Chinese scholars mostly just studied
FDI in very general terms, not having subdivided FDI into types.

This paper adopts analytical frame of Dixit \& Stiglitz (1977), and tries to build up a more comprehensive theoretical model of vertical FDI location, which thus provide a theory basis for the fulfillment of formulating FDI policy in host country.

\section{BASIC MODELS}

The classic model of Dix it \& Stiglitz (1977) built up an analytical frame of monopolistic competition and product diversification on the abstract level; Krugman (1991b) led the space factor into the D-S model, built up so-called "The centre-periphery model". The model probes into the decision-making factors of enterprise on its location from microcosmic foundation, explains the phenomenon of various economic activities gathering together in one region on macroscopic layer. This paper takes the two regions- two sectors of the monopolistic competition general-equilibrium model by Krugman(1991b) for basic and analytical frame, investigates the following factors: (1) wage cost;(2) transaction cost; (3) agglomerative economy; (4) market scale; (5) the quality of labor force, which functions acted on the vertical FDI.

\section{A. Basic Assumptions}

A vertically integrated multinationals mean that it breaks the perpendicular production chain, installs the different stage of the production at different nation. For simplifying analysis, suppose the multinational enterprises can split production course into two stages, which establishing the headquarters, $R \& D$ center in developed country where information, funds, persons with ability and establishments for communicating business are intensive, establishing the production activity needed large amount of non- skilled labor force in developing country where labor force is abundant. A horizontally integrated multinationals mean that parent company substitutes localized production for exporting, the aim is for reducing the cost within supplying market process (such as tariff and freight), or raising its competition ability in local market in other way (such as shorter delivery time and ability of responding to the local market circumstance and preference).

A vertical integrated multinationals means with " $v$ ". A horizontal integrated multinationals means with " $h$ ". A domestic enterprise that the factory and the headquarters all establish at a country means with "d", which doesn't produce by multinational way but adopts the way of exporting products only.

Using "m" represents mother country, " $\mathrm{f}$ " represents host country. Consider two-region economy, in this 
economy, existing two sectors, namely the agriculture sector and modern industry sector.

The utility of each consumer in the mother country adopts the Cobb-Douglas utility function as follows:

$$
U_{m}=M_{m}^{\mu} A_{m}^{1-\mu}
$$

The utility function of each consumer in the host country is as follows:

$$
U_{f}=M_{f}^{i} A_{f}^{1-u}
$$

Among them, $M_{m}$ and $A_{m}$ respectively measures to the consumption of industrial goods aggregation and agricultural goods by a consumer of mother country. $M_{f}$ and $A_{f}$ respectively measures to the consumption of industrial goods aggregation and agricultural goods by a consumer of host country.

Suppose any two kinds of industrial goods has the same substitution elasticity whether in mother country or in host country, thus the sub-utility that the consumer gets to consume the industrial goods aggregation can take the CES function as :

$$
\begin{aligned}
& M_{m}=\left(\sum_{i=1}^{n_{m}} C_{i m}^{(\delta-1) / \delta}\right)^{\delta /(\delta-1)} \\
& M_{f}=\left(\sum_{i=1}^{n_{h}} C_{i f}^{(\delta-1) / \delta}\right)^{\delta /(\delta-1)}
\end{aligned}
$$

$C_{i m}$ for consumption quantity of the industrial good " $i$ " by a consumer of mother country , and $C_{i f}$ for consumption quantity of the industrial good " $\mathrm{j}$ " by a consumer of host country, $\boldsymbol{n}_{\boldsymbol{m}}$ and $\boldsymbol{n}_{f}$ respectively for the numbers of industrial goods kinds that consumed in mother country and in host country., $\delta>1$.

\section{B. The consumption decision of the consumer}

Consider the consumer decision of the mother country first. The first stage, the consumer chooses the combination of industrial goods and the agricultural consumed under income level constraint, makes his utility maximized.

$$
\begin{aligned}
& \max M_{m}^{\mu} A_{m}^{1-\mu} \\
& \text { s.t. } A_{m}+I_{m} M_{m}=Y_{m}
\end{aligned}
$$

Make the price of agriculture goods as 1 and the price of industrial goods aggregation as $I_{m}, Y_{m}$ is income level of the consumer, then get the budget constraint formula (6). According to standard solution of maximum problem, build up Lagrange function, we can get follows:

$$
I_{m} M_{m}=\mu Y_{m} \quad A_{m}=(1-\mu) Y_{m}
$$

At the second stage, the consumer makes sub-utility maximized by choosing $c_{i m}$ under the budget constraint of formula (9), $p_{i m}$ is the price of industrial goods " $i$ " in mother country.

$$
\begin{aligned}
& \max \left(\sum_{i=1}^{n} C_{i m}^{\frac{(\delta-1)}{\delta}}\right)^{\frac{\delta}{(\delta-1)}} \\
& \text { s.t. } \sum_{i=1}^{n} p_{i m} c_{i m}=\mu Y_{m}
\end{aligned}
$$

We can know from consumer's maximizing utility behaviors, the demand function of a representative consumer to industrial good " $i$ " in mother country is:

$$
c_{i m}=p_{i m}^{-\delta}\left(I_{m}^{\delta-1} \mu Y_{m}\right)
$$

In formula (10) $I_{m}$ is the price index of industrial goods of the mother country,

$$
I_{m}=\left(\sum_{i=1}^{n_{m}} p_{i m}^{(1-\delta)}\right)^{1 /(1-\delta)}
$$

Suppose $L_{m}$ is the total population of mother country , then the demand function of mother country to industrial good " $i$ " is:

$$
x_{i m}=L_{m} c_{i m}=L_{m} p_{i m}^{-\delta}\left(I_{m}^{\delta-1} \mu Y_{m}\right)=k_{m} p_{i m}^{-\delta}
$$

In formula (12), make $k_{m}=L_{m} I_{m}^{\delta-1} \mu Y_{m}$.

Similarly, suppose $L_{f}$ is the total population of host country, $p_{i f}$ is the price of industrial goods " $i$ " in host country, then the demand function of host country to industrial good " $i$ " is:

$$
x_{i f}=k_{f} p_{i f}^{-\delta}
$$

In formula (14), $\boldsymbol{k}_{f}=\boldsymbol{L}_{f} \boldsymbol{I}_{f}^{\delta-1} \boldsymbol{i} Y_{f}, \boldsymbol{I}_{f}$ is the price index of industrial goods of the host country.

\section{The production decision of the manufacturer}

Suppose exists economics of scale but doesn't exist economics of scope in any industrial goods production, then each firm produces a kind of product only. And suppose only non-skilled labor the kind of production factor is used in production course, regardless any type enterprise "d", "v" or "h" has the same production function, which is as follows:

$$
l_{i s}=\alpha+\beta x_{i s} \quad(s=d, v, h)
$$

$l_{i s}$ is the amount of labor that the "s" type enterprise produces product " $i$ " to use, $x_{i s}$ is the quantity of product " $i$ " by the "s" type enterprise, $\alpha$ is the fixed cost of the factory taking worker labor quantity as the measurement unit, $\beta$ is the marginal cost taking worker 
labor quantity as the measurement unit. Mean the fixed cost of company with $\mathrm{F}$.

If a " $d "$ type enterprise, it doesn't produce by multinational way but adopts the way of exporting products only, and the wage level of mother country is $w_{m}$, then its profits function to produce product " $i$ " is:

$$
\begin{aligned}
& \pi_{i d}=p_{i m} x_{i d}-w_{m}\left(\alpha+\beta x_{i d}\right)-F \\
& s \cdot t \cdot \quad x_{i d}=x_{i m}+\tau x_{i f}
\end{aligned}
$$

In above formula $w$ is the wage level of mother country, $x_{i d}$ means the output of product " $i$ " by the " $\mathrm{d}$ " type enterprise, $p_{i d}$ means the price of product " $i$ " by the "d" type enterprise. Formula (16) means that the output by the " $d$ " type enterprise is equal to the local demands and the delivered demands to host country.

Introducing the iceberg transactions technique, suppose for delivering one unit of industrial goods to another district, it needs to deliver $\tau$ units from this district, namely the transactions costs between mother country and host country is $(\tau-1)$.Here the transaction costs not only include actual paying expenses in transporting, also include various costs that caused by trade obstacles between different regions. Thus the firm of mother country will take the price of $\tau p_{i d}$ to sale product in host country. Formula (18) means that the output by the "d" type enterprise is equal to the local demands and the delivered demands to host country.

Take formula (12), (13) into (16), and then into "d" type enterprise profits function (17), we can get follows:

$$
\pi_{i d}=\left(p_{i m}-w_{m} \beta\right)\left(k_{m} p_{i m}^{-\delta}+k_{f} \tau^{1-\delta} p_{i m}^{-\delta}\right)-w_{m} \alpha-F
$$

Build up Lagrange function, $\pi_{i d}=p_{i d} x_{i d}-w\left(\alpha+\beta x_{i d}\right)-F+\lambda\left(x_{i d}-L_{m} k p_{i d}^{-\delta}+L_{f} k^{\prime} \tau^{1-\delta} p_{i d}^{-\delta}\right)$, from the first rank conditions gets follows:

$$
p_{i m}=\frac{w_{m} \beta}{1-\frac{1}{\delta}}=\frac{w_{m} \beta}{\rho}=\rho^{-1} w_{m} \beta
$$

Take formula (18) into formula (12), (13), then into (16), formula (19) can be got:

$$
x_{i d}=k_{m} \rho^{\delta}\left(w_{m} \beta\right)^{-\delta}+k_{f} \rho^{\delta} \tau^{1-\delta}\left(w_{m} \beta\right)^{-\delta}=\rho^{\delta}\left(w_{m} \beta\right)^{-\delta}\left(k_{m}+k_{f} \tau^{1-\delta}\right)
$$

Take formula (18), (19) into formula (15) will get the profits of the " $\mathrm{d}$ " type enterprise that produces the product " $i$ ":

$$
\pi_{i d}=(1-\rho)\left(\frac{w_{m} \beta}{\rho}\right)^{1-\delta}\left(k_{m}+k_{f} \tau^{1-\delta}\right)-w_{m} \alpha-F
$$

If a " $v "$ type enterprise, its outputs are equal to the local demands and the delivered demands to mother country.

$$
x_{i v}=\tau x_{i m}+x_{i f}
$$

Using $w_{f}$ represents the wage level of host country, the profits function of " $\mathrm{v}$ " type enterprise that produces the product " $i$ " is:

$$
\pi_{i v}=p_{i f} x_{i v}-w_{f}\left(\alpha+\beta x_{i v}\right)-F
$$

Similarly,

$$
p_{i f}=\frac{w_{f} \beta}{1-\frac{1}{\delta}}=\rho^{-1} w_{f} \beta
$$

Take formula (23) into formula (12), (13), then into (21) will get:

$$
x_{i v}=(\rho)^{\delta}\left(w_{f} \beta\right)^{-\delta}\left(k_{m} \tau^{1-\delta}+k_{f}\right)
$$

Take formula (23), (24) into formula (22) gets the profits of " $v$ " type enterprise that produces the product " $i$ ":

$$
\pi_{i v}=(1-\rho)\left(\frac{w_{f} \beta}{\rho}\right)^{1-\delta}\left(k_{m} \tau^{1-\delta}+k_{f}\right)-w_{f} \alpha-F
$$

If an " $\mathrm{h}$ " type enterprise, its profits function is:

$$
\pi_{i h}=p_{i m} x_{i m}+p_{i f} x_{i f}-w_{m}\left(\alpha+\beta x_{i m}\right)-w_{f}\left(\alpha+\beta x_{i f}\right)-2 F
$$

Take formula (12), (13), (18), (23) into formula (26) gets the profits of " $\mathrm{h}$ " type enterprise:

$$
\pi_{i h}=(1-\rho)\left(\frac{\beta}{\rho}\right)^{1-\delta}\left(k_{m} w_{m}^{1-\delta}+k_{f} w_{f}^{1-\delta}\right)-\left(w_{m}+w_{f}\right) \alpha-2 F
$$

The firm chooses for a vertically integrated multinationals must satisfy the following two conditions: (1) $\pi_{i \mathrm{v}}>\pi_{i d}$; (2) $\pi_{i v}>\pi_{i \mathrm{~h}}$. Namely:

$$
\begin{aligned}
& \pi_{i v}-\pi_{i d}=(1-\rho)\left(\frac{\beta}{\rho}\right)^{1-\delta}\left\{\begin{array}{l}
{\left[\left(w_{f}\right)^{1-\delta}-\left(\tau w_{m}\right)^{1-\delta}\right] \cdot k_{f}} \\
+\left[\left(\tau w_{f}\right)^{1-\delta}-w_{m}^{1-\delta}\right] \cdot k_{m}
\end{array}\right\}+\left(w_{m}-w_{f}\right) \alpha>0 \\
& \pi_{i v}-\pi_{i h}=(1-\rho)\left(\frac{\beta}{\rho}\right)^{1-\delta} L_{m} k_{m}\left[\left(\tau w_{f}\right)^{1-\delta}-w_{m}^{1-\delta}\right]-w_{m} \alpha>0
\end{aligned}
$$

\section{ANALYSIS ON LOCATION CHOICE OF THE VERTICAL FDI FROM MULTINATIONAL ENTERPRISES}

The above two formulae announced some most important factors to influence the choice of the enterprises. We set off the analysis to these. 


\section{A. Wage Cost}

Formula (28) consists of two parts. Part II is the variety of production costs when the firm chooses the mode of vertical multinational production relative to the mode of domestic production. Part I in formula (28) is net variety of revenue subtract from transaction costs when the firm chooses vertical multinational production relative to chooses domestic production. $\pi_{i v}-\pi_{i j}$ and $\pi_{i v}-\pi_{i h}$ may be bigger than zero, or may be smaller than zero, this is decided by wages level of two countries.

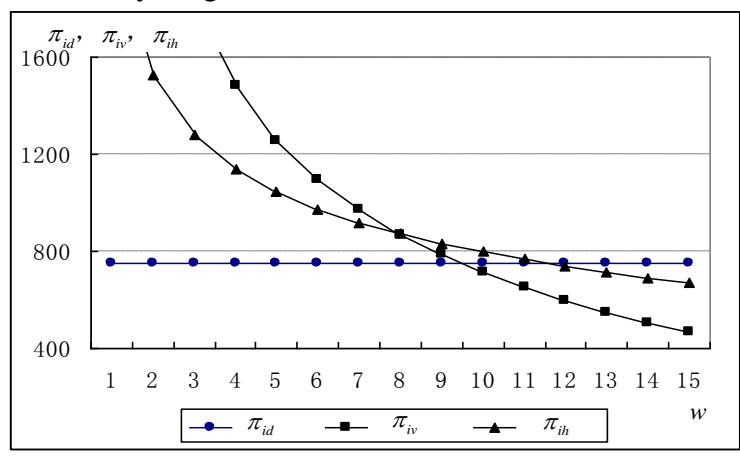

Figure 1. Location Choice of FDI: Basic Circumstance

Fig. 1 is the emulation result of this model; the Horizontal stalk represents the wage rate of the investment location in host country. From fig. 1 it is thus clear that, if the firm chooses the mode of vertical multinational production, $w_{f}$ is by no means surpassing a certain limits. The vertical FDI is the result that developed country chooses developing countries; it flows to the developing countries which economic development levels are at a certain stage generally.

\section{B. Transaction costs}

The smaller $\tau$ is, the bigger $\pi_{i v}$ is, the more motive force the firm has to choose the mode of vertical multinational production. When other conditions are equal, lower transaction cost will accelerate the multinationals to carry on a vertically direct investment in the host country, but higher transaction cost will repress vertical FDI.

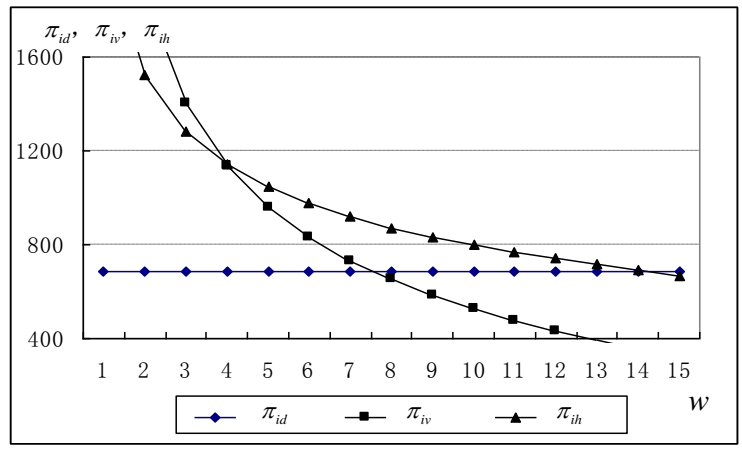

Figure 2. Location Choice of FDI: When Transaction Cost Rises

Fig. 2 is the emulation result while transaction cost rises. It can be seen while transaction cost rises; the investment location of vertical FDI is requested to have further cost advantage than the basic circumstance. It also can be said only when some periphery nation or region have lower advantages of wages rate enough to make up disadvantage away from the bigger market and supplier, vertically FDI just has motive to leave centre to relocate in periphery.

\section{Market scale}

Although $\pi_{i v}$ increases along with market scale enlarging, but $\pi_{i d}$ and $\pi_{i h}$ increase at the same. So what will the aggrandizement of market scale affect location choice of the vertical FDI from the multinationals?

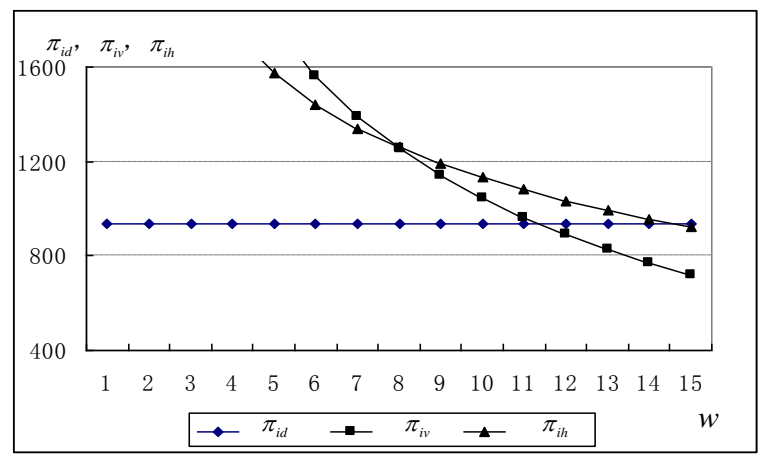

Figure 3. Location Choice of FDI: When Scale of Market Increases 100\% than Basic Circumstance

Fig. 3 is the emulation result when market scale aggrandizes $100 \%$ than it of the basic circumstance. Compare Fig.3with the basic circumstance (Fig. 1), we can discover an interesting phenomenon that aggrandizement of market scale has almost no influence on the investment location of vertical FDI, and the investment location of vertical FDI is still requested to satisfy the beginning low cost condition. Therefore, market scale has influence on $\pi_{i v}$, but has no influence on the location choice of vertical FDI.

\section{Agglomerative Economy}

$\mu$ 'represents the industrialization level of a region. The rise of the industrial quota in a region explains that industrial agglomerations have occurred there. Industrializing level can be regarded as the index to measure agglomerative economic effect of a region. The bigger $\mu$ is, the greater agglomerative economic effect is; and the bigger $\pi_{i v}$ also is. Therefore, agglomerative economic effect brings positive influence to vertical FDI. Agglomeration of production make transferring of knowledge more convenient and faster; raise the efficiency of supplying network and circulating network, which make the business enterprises enjoy the advantage brought by the scale economy and scope economy. It is thus clear that agglomerative economy plays an important role in attracting FDI to the host country. It Is especially said by Porter "the reason why a region has attraction to directly investment from the multinationals, lies in its infrastructure, service facilities and well-trained labor force, having good regional image and a great deal of industrial concentration etc."

\section{E. Quality of Labor Force}

The smaller $\beta$ is, the higher the productivity of Labor is, the bigger $\pi_{i v}$ is, the more motive force the firm has to choose the mode of vertical multinational production. The 
smaller $\beta$ is, the higher quality of labor force in the host country is, which have positive function on the inflowing of vertical FDI. Skilled labor force in the host country is the direct need of the multinationals, which influence the inflowing of FDI. If developing countries lake welltrained labor force, particularly in regular education and training, which will limit the inflowing of foreign capital.

\section{CONCLUSION}

According to above-mentioned analysis, this paper mainly gets the following two conclusions:

\section{ACKNOWLEDGMENTS}

This work is supported by Liaoning province social science fund plan "Research on the problems and countermeasures of Liaoning province enterprises 'going out' strategy (L13BJY024)".

\section{REFERENCES}

[1] Gordon L. Clark, Maryann P. Feldman, and Meric S. Gertler, The Oxford Handbook of Economic Geography [M], Oxford University Press, 2003.

[2] Wei,Hou-kai, He,Chan-fei and Wang-Fei, Investment location decision of foreign companies in China and public policies[M] (in Chinese), MA: Commercial Press,2002.

[3] Zheng,Jing-shu, The location system of the modern multinational companies and economy of the worlds, MA: Zhongshan university press, 2004.

[4] Dixit, A.K.and J.E.Stiglitz, Monopolistic Competition and Optimum Product Diversity [J], American Economic Review, 1977, 67(3): 297-308.

[5] Fujita, Masahisa, Paul Krugman, and Anthony J.Venables, the Spatial Economy: Cities, Region, and International Trade [M], Cambridge, MA: the MIT Press, 1999.

[6] Krugman, Paul. , Geography and Trade [M], MA: MIT Press, 1991.

[7] Krugman, Paul. , Increasing Return and Economic Geography [J], Journal of Political Economy, 1991, 99(3):483-499.

[8] Ottaviano, G. I. P. And D. Puga, Agglomeration in the Global Economy: A Survey of the "New Economy Geograpgy" [J], the World Economy, 1998, 21(6): 707-731.
The vertical FDI is the result that the developed country chooses to developing countries, it flows to the developing countries which economic development level are at a certain stage generally, this conclusion agrees with actualities. Under the conditions for vertical FDI entering into, along with the lower of wage level, elasticity of substitution, marginal costs and transaction costs, and the higher of population scale, expenditure proportion of industrial goods and income level of host country, the scale of vertical FDI to host country will more and more big.

[9] Markusen, James R., and Anthony J. Venables, The Theory of Endow ment, Intra-Industry and Multinational Trade [J], Journal of International Economics, 2000, 52(2): 209-234.

[10] Kevin Honglin Zhang and James R. Markusen, Vertical Multinationals And Host-Country Characteristics [J], Journal of Development Economics, 1999, 59(2): 233-252.

[11] [S. Lael Brainard and David Martimort, Strategic Trade Policy with Incompletely Informed Policymakers [J], Journal of International Economics, 1997, 42(1-2): 33-65.

[12] Gene M. Grossman, Elhanan Helpman and Adam Szeidl, Optimal Integration Strategies for the Multinational Firm [J], Journal of International Economics, 2006, 70(1): 216-238.

[13] Gong, H, M., Spatial Patterns of Foreign Investment in China's Cities: 1980-1989 [J], Urban Geography, 1995, 16(3):189-209.

[14] Head, K., J. Rise, Inter-city Competition for Foreign Investment: Static and Dynamic Effects of China's Incentives Areas [J], Journal of Urban Economics, 1996, 40(1): 38-60.

[15] F.Barry, H.Gorg and E.Strobl, Foreign Direct Investment, Agglomerations and Demonstration Effects: An Empirical Investigation [J], Research Paper Series, 2001, 25(1):.78-109.

[16] Luger, M. and Shetty, S., Determinants of Foreign Plant Start-ups in the United States: Lessons for Policy-makers in the Southeast [J], Vanderbit Journal of Transnational Law, 1985, 18(2):223-245.

[17] Coughlin, C., J. Terza and V. Arromdee, State Characteristics and the Location of FDI within the United States [J], Review of Economics and Statistics, 1991, 73(4):675-683.

[18] Ottaviano, G. And Tabuchi, T. and Thisse, J-F. , Agglomeration and trade revisited, International Economic Review [J], vol 43, pp. $409-436,2002$. 